\title{
The Missing Link \\ Bicycle Infrastructure Networks and Ridership in 74 US Cities
}

\author{
Jessica E. Schoner · David M. Levinson
}

Received: date / Accepted: date

\begin{abstract}
Cities promote strong bicycle networks to support and encourage bicycle commuting. However, the application of network science to bicycle facilities is not very well studied. Previous work has found relationships between the amount of bicycle infrastructure in a city and aggregate bicycle ridership, and between microscopic network structure and individual tripmaking patterns. This study fills the missing link between these two bodies of literature by developing a standard methodology for measuring bicycle facility network quality at the macroscopic level and testing its association with bicycle commuting. Bicycle infrastructure maps were collected for 74 United States cities and systematically analyzed to evaluate their network structure. Linear regression models revealed that connectivity and directness are important factors in predicting bicycle commuting after controlling for demographic variables and the size of the city. These findings provide a framework for transportation planners and policymakers to evaluate their local bicycle facility networks and set regional priorities that support nonmotorized travel behavior, and for continued research on the structure and quality of bicycle infrastructure and behavior.
\end{abstract}

Keywords Bicycling · Travel Behavior · Networks

\section{Author Bios}

Jessica Schoner is a doctoral student in the University of Minnesota Department of Civil Engineering. Her current research focuses on mutual causality between bicycling and infrastructure, and travel behavior of bicyclists and bike share users.

David Levinson is a professor in the University of Minnesota Department of Civil Engineering and director of the Nexus research group. His current research focuses on under-

J. Schoner

Department of Civil Engineering, University of Minnesota, 500 Pillsbury Drive SE, Minneapolis, MN 55455, USA

E-mail: schon082@umn.edu

D. Levinson

Department of Civil Engineering, University of Minnesota, 500 Pillsbury Drive SE, Minneapolis, MN 55455, USA

E-mail: dlevinson@umn.edu 
standing the process of network growth, evaluating transportation technology and policy, and modeling travel behavior.

\section{Introduction}

Cities are increasingly promoting cycling as a valuable transportation alternative to driving, arguing that mode shift away from the private auto provides region-wide congestion, environmental, and health benefits (Federal Highway Administration, 2012). Between 1999 and 2011, total United States (US) federal and state government funding on bicycling and pedestrian infrastructure exceeded \$7 Billion. The US Federal Highway Administration (FHWA) completed the Nonmotorized Transportation Pilot Program in 2012, which allocated \$25 Million to each of four pilot cities over five years to measure the impacts of new infrastructure on mode shift to bicycling and walking (Federal Highway Administration, 2012). Many projects are explicitly targeted at closing "gaps" in bike routes to form a more cohesive cycling network (Byers, 2002). This idea of a "network" of bicycle routes connecting the region is an important indicator of the shift in transportation priorities from auto dominance to accommodation of nonmotorized modes. While bicycles are permitted to use most components of the road network in the US, bicycle-specific infrastructure provides safe, comfortable routes that many bicyclists prefer over sharing travel lanes with motorized vehicles. The network formed by bicycle-specific infrastructure in any given city, however, is not as expansive or complete as the underlying road network, so cyclists often have to detour to stay on dedicated facilities or else share the roadway with car and trucks in order to complete their trip.

Numerous studies have identified relationships between rates of bicycling and provision of infrastructure (Nelson and Allen, 1997; Dill and Carr, 2003; Parkin et al, 2007; Buehler and Pucher, 2011). Qualitative descriptions of bicycle facility network characteristics and planning priorities are prevalent in practice (American Association of State Highway and Transportation Officials, 2012). However, the application of quantified network structure indicators to bicycle infrastructure design and research is nascent. This paper aims to fill this gap in the literature by developing a protocol for evaluating bicycle infrastructure network structure and testing its predictive power on bicycle commuting mode share. Understanding these relationships between bicycle commuting and bicycle network features will enable transportation and planning agencies to target investment in infrastructure components for optimum impact on existing riders and potential future bicyclists.

This paper analyzes bicycle facility networks from 74 mid- to large-sized cities in the US, mapped in Figure 1 to identify, quantify, and evaluate the backbone network of dedicated bicycling infrastructure. Five network structure factors are constructed from a series of graph theory measures. Regression models are used to test the relationship between these factors and bicycle commuters per 10,000 workers, controlling for city population, land area, median income, household structure, college enrollment, and auto ownership. This paper is organized as follows: Section 2 discusses literature on the relationships between infrastructure and bicycling. Section 3 explains the data collection process, network structure measures, and factor analysis. Section 4 describes results from two linear regresson models of bicycle commute share and the sensitivity of bicycle commuting to variables estimated in the model. Finally, Section 5 outlines implications for practice and opportunities for further study. 


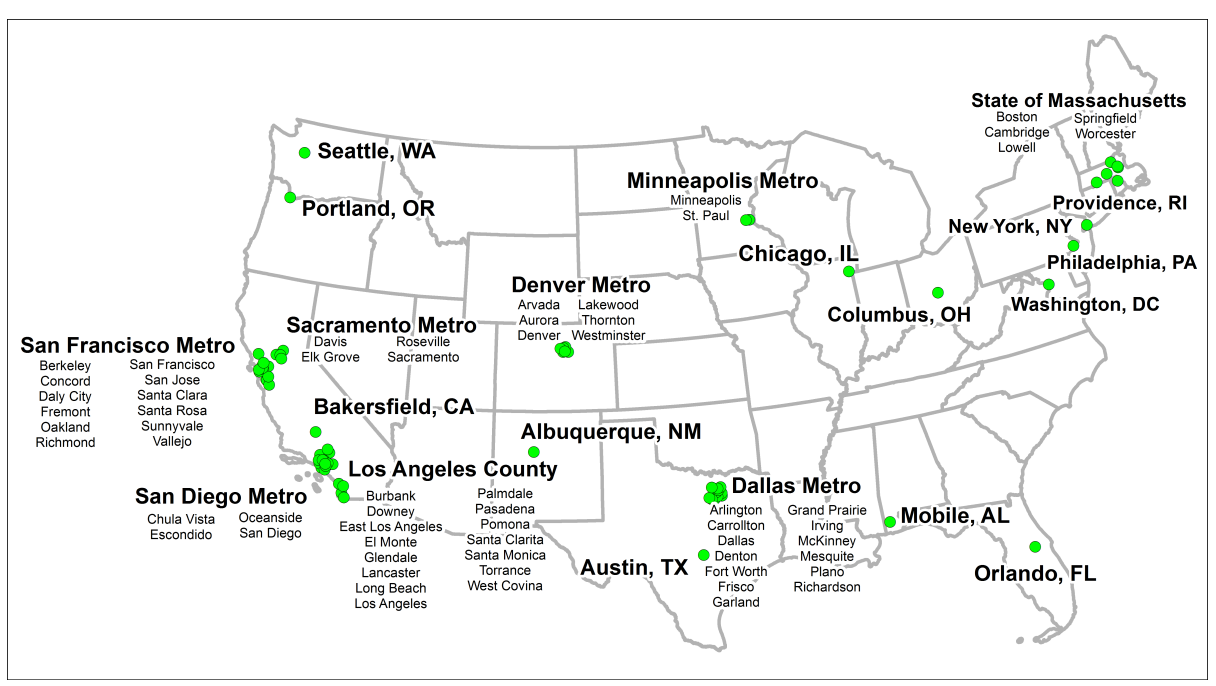

Fig. 1: 74 US Cities Included in Sample

\section{Literature Review}

Planners and researchers have long sought evidence about the relationship (if any) between certain types of infrastructure induce bicycling, and the needs of beginner bicyclists. The evidence for bicycle facilities inducing mode shift is weak, but there is strong evidence for dedicated facilities shifting individuals' route choice calculus, attracting bicyclists from unimproved routes (Pratt et al, 2012). Pucher et al (1999)'s review of bicycling literature failed to find statistically rigorous studies that establish causality between infrastructure development and induced cycling. The prevalence of extensive and highly connected cycling infrastructure networks in Europe correlates with high rates of bicycling, but the authors posited that the facility development might follow cyclists rather than incite cycling (Pucher et al, 1999; Buehler and Pucher, 2012). A longitudinal study of infrastructure development and rates of commuting by bicycle in the Minneapolis-St. Paul Metro Area reached almost the same conclusion (Krizek et al, 2009): Most new facilities were installed in areas that already had much higher than average levels of cycling, with one exception. The University of Minnesota Transitway, a dedicated roadway exclusively for university-operated transit vehicles and bicycles connecting the Minneapolis and St. Paul campuses, made longer cycling commute trips viable, enabling people to switch to cycling for their work or school commutes (Krizek et al, 2009).

\subsection{Facilities and Individual Behavior}

Bike lanes and trails are still a recommended strategy for increasing cycling because studies have found a significant correlation between bicycling behavior and dedicated facilities, even if evidence for causality is limited. Wilkinson et al (1994), in their Federal Highway Administration (FHWA) manual on roadway design treatments for bicyclists, recommend providing bicycle facilities that both serve existing bicyclists and encourage new riders. They argue that a supply-driven approach of facilities targeted at basic cyclists (Group B) 
and children (Group C) will encourage mode shift to cycling and use of the facilities. Evidence about which network elements serve bicyclists best is mixed, though it is clear that dedicated infrastructure adds value for all types of bicyclists. Tilahun et al (2007) found that stated preference survey respondents in the Minneapolis-St. Paul Metro Area valued a bike lane improvement as equivalent to saving about 16 minutes from a baseline 20-minute trip. In Beijing, Zhao (2013) found that a $1 \%$ increase in exclusive bike lanes corresponded to a $0.19 \%$ increase in the probability of choosing to bicycle. Despite expressed willingness to detour in stated preference surveys, bicycle commuters are shown to be highly sensitive to distance (Handy and Xing, 2011), so building a network that provides direct connections with minimal detour is important. A network that requires substantial detour undermines its own utility by increasing travel distance for a population known to be particularly sensitive to distance. Wilkinson et al (1994) recommended a network of bike lanes, separated paths, and bike boulevards, or quiet local streets parallel to major corridors with improvements to calm auto traffic and encourage bicycling, to connect Group B/C cyclists to their destinations (Wilkinson et al, 1994; American Association of State Highway and Transportation Officials, 2012).

Some studies have found that advanced cyclists (Group A) value reduced travel time and directness, suggesting that their needs are significantly different from B/C cyclists and are sufficiently served with wide shoulders and consistent speed limit enforcement (Wilkinson et al, 1994; Stinson and Bhat, 2005; American Association of State Highway and Transportation Officials, 2012). However, other scholars have found evidence that even enthusiastic and confident bicyclists receive some benefit from bike lanes and trails. Dill (2009) used GPS devices to study bicyclist route choice and discovered that a disproportionate share of bicycle miles traveled occurred on dedicated facilities, suggesting that even experienced cyclists will trade route efficiency for safety and comfort. Caulfield et al (2012)'s stated preference route choice model in Dublin found that off-street trails and green lanes increased the chances of a route being chosen relative to a traditional bike lane, and this finding applied even after stratifying their sample by bicyclist confidence level (ranging from "completely confident" to "not at all confident"). These findings are not mutually exclusive. Some confident cyclists may feel that streets without bicycle improvements adequately serve their needs, but dedicated infrastructure provides a more comfortable route alternative when they choose to use it. In any case, it is clear that cyclists of all levels prefer and use bike lanes and trails over mixed traffic.

Of course, the value of dedicated bicycle facilities can be highly context dependent. Several authors have noted that the presence of on-street parking reduces the utility of bike lanes, for example (Tilahun et al, 2007; Sanders, 2014). Klobucar and Fricker (2007) used a bicycle compatibility index based on traffic volumes and travel speeds to model the effects of distributing bike lanes on streets with high or low compatibility scores. Additionally, low traffic and low speed streets, particularly without street parking, can be just as useful or even moreso than some types of dedicated infrastructure. The recently revised "Guide for the Development of Bicycle Facilities" published by American Association of State Highway and Transportation Officials (2012) describes bicycle network planning as a process involving comprehensive qualitative and quantitative assessment of existing conditions, needs, and feasibility. No single facility type serves all roadway contexts and user needs. Whatever the appropriate facility type, the Guide recommends that routes be direct with as few detours as possible, and bikeway density should be planned for maximum use and comfort (e.g., within one quarter mile of every resident). Complete streets policies are recommended to encourage consideration of bicyclists' needs during any road resurfacing or maintenance project (American Association of State Highway and Transportation Officials, 2012). 


\subsection{Cross-Regional Studies}

Cross-regional studies have found positive relationships between the size of a city's bicycle facility network and its bicycle commute share. Nelson and Allen (1997) found that each additional mile of bikeway per 100,000 people was associated with a 0.069 to 0.075 percent increase in commuters using bicycles across 18 US cities. Dill and Carr (2003), using an expanded dataset of 50 cities, found each additional mile of facility per square mile of city area to be associated with a one percentage point increase in bike commuting.

Rietveld and Daniel (2004) performed a similar type of study modeling bicycle share of use in 103 cities in the Netherlands, though instead of measuring the quantity of bicycle facilities, they used several measures of infrastructure quality developed by the Dutch Cyclists' Union (Fietsersbond). They found the number of stops and hindrances per kilometer on any given trip were both negatively associated with bicycle share. If the travel time via bicycle for a trip was $10 \%$ faster than by car, then bicycle use for that trip increased $3.4 \%$. They concluded that bicyclists are sensitive to the speed and directness of their routes, so city policy that makes bicycle trips easier and more efficient will increase rates of cycling.

Parkin et al (2007)'s study of bicycle commuting in English and Welsh electoral wards found a positive, significant association between proportion of off-street bicycle routes and ridership, but they noted that the elasticity was small: only about 0.049 , suggesting that a disproportionately large quantity of off-street routes would need to be built to see only a modest increase in bicycling. They also assert a bicycling saturation point of $43 \%$, though this was considerably higher than the maximum observed in their study. Buehler and Pucher (2011)'s findings from a study of 90 US cities corroborate this evidence: they found a $10 \%$ increase in supply of bike lanes is associated with only a $3.1 \%$ increase in the number of bike commuters per 10,000 residents. For off-street paths, the increase was only $2.5 \%$.

The missing link in many studies is the quality of the network formed by the infrastructure: Can a cyclist complete her desired trip using the bicycle network without significant detours or discontinuities that would require riding in unsafe or uncomfortable conditions? Most of the cross-regional studies conducted to date have focused on quantity or density of infrastructure, with no evaluation of how well connected the infrastructure is. Rietveld and Daniel (2004)'s study addressed network quality indirectly by measuring barriers along trips, but their variables did not directly measure connectivity.

Mekuria et al (2012)'s analysis of "low stress" networks clearly demonstrates the importance of connectivity by evaluating the quality of routes holistically by their weakest link rather than an average or index. From this perspective, a route that is almost entirely comprised of off-street trails but requires crossing major streets at a few hostile intersections would be inaccessible for someone whose tolerance threshold is lower than those intersections would support. However, the focus is on microscopic street characteristics rather than a macroscopic summary of bicycle facilities.

\subsection{Graph Theory and Bicycling}

While it is not expected that a bicyclist complete $100 \%$ of their trip exclusively on dedicated infrastructure, lanes and trails form a backbone network for bicycling in a city. Thus the utility of dedicated infrastructure is closely related to what level of connectivity it provides. Planning for isolated infrastructure segments without considering how these pieces of infrastructure connect to the broader street network undermines the potential utility of 
this infrastructure. Discontinuities in the bicycle network may have three potential consequences:

1. Forcing the cyclist into mixed traffic

2. Requiring lengthy detours to avoid mixed traffic

3. Discouraging cycling altogether

Graph theory offers systematic methods for measuring network quality for comparison across cities and to see its effect on travel behavior. Garrison and Marble (1962) first introduced graph theory principles to transportation geography. Kansky (1963) presents the alpha index $(\alpha)$, beta index $(\beta)$, and gamma index $(\gamma)$ in his dissertation as ratios that describe the relationship between distinguishable elements of a graph.

Graph theory measures applied to transportation are now fairly common in transportation research (Xie and Levinson, 2007; Derrible and Kennedy, 2009; Rodrigue et al, 2009). Simple measures, such as street density or cul-de-sac density, are frequently used to characterize the built environment and model travel behavior. For example, Parthasarathi et al (2013) found that increased street density was associated with longer perceived travel times for drivers. While one might hypothesize the relationship to be a bit more complex for nonmotorized road users, this application illuminates the possible mechanisms by which network connectivity may influence travel behavior.

Several studies have used graph theory measures to explain individuals' nonmotorized travel behavior. Berrigan et al (2010) measured the link-node ratio and several graph theory indices of the local street grid within short buffers around survey respondents' home addresses. These measures factored into two main variables of network quality that predicted propensity and duration of active transportation. Dill and Voros (2007) found significant differences between the connected node ratios people who biked the previous summer and people who did not. Network quality and connectivity have been evaluated at a microscopic level by studying individual discontinuities in on-street bicycle facilities and long-term network development at gaps and critical points (Krizek and Roland, 2005; Birk and Geller, 2006; Barnes and Krizek, 2005).

These studies significantly advanced our understanding of bicycle infrastructure quality, while previously described research (Nelson and Allen, 1997; Dill and Carr, 2003; Rietveld and Daniel, 2004; Parkin et al, 2007; Buehler and Pucher, 2011) set a precedent for modeling a population's use of bicycling as a function of infrastructure availability. This study fills the missing link between these two bodies of research by (1) adapting existing graph theory and transport geography measures to describe a city's bicycle infrastructure network, (2) measuring the quality of bicycle networks using a newly assembled collection of spatial data from 74 US cities, and (3) modeling bicycle commuting as a function of these measures, controlling for several common demographic correlates of cycling.

\section{Methodology}

\subsection{Data Collection and Assembly}

In this study, we collected spatial data and American Community Survey (ACS) household, demographic, and journey to work data for 74 mid- and large-sized cities in the US. The sampling frame consisted of US cities for which a spatial dataset of bicycle infrastructure was publicly available, and the data was organized in a usable format (ESRI Shapefile or Keyhole Markup Language). 
Cities were only included if it was possible to distinguish separate bicycle facilities (lanes, side paths, paved trails) from mixed-traffic facilities (shared lane markings, signed bike routes, bike boulevards) as only the separate facilities were included in the analysis. As described in Section 2.1, the appropriate facility type for any given corridor depends heavily on local context. Selecting only specific types of infrastructure for network analysis means that the quality of bike networks in cities that make contextually appropriate use of other types of infrastructure may be underestimated.

Several large metro areas provided data for all their member cities in one file. These shapefiles were disaggregated to the city level and then considered for analysis. Adjacent cities may share bicycle travel (e.g., a resident of City A commutes to City B for work), so these cases would violate the assumptions of independence in regression modeling. To reduce the impact of this phenomenon on the study, only cities with population greater than 100,000 were retained from disaggregated metro areas. This has two effects: sampling only a portion of cities reduces the chances that adjacent cities will be included (though not as well as a random sample), and using only larger cities increases the chance that any given commuter starts and ends their journey in the same city.

Many of the bicycle infrastructure network files had geometry inconsistencies arising from how they were created, such as dangling ends where two edges should meet at a single vertex. To reduce the possible impacts of errors and subtle digitization differences across cities, we cleaned the shapefiles using a model routine in ArcGIS to trim dangling ends less than 5 meters, extend ends to fill gaps less than 5 meters, remove excess verticies, and dissolve single network features that were represented with multiple segments.

The final sample included 74 US cities, covering 22 of the top 50 most populous. These cities are shown in Figure 1. Where multiple cities from the same metro area are included, the city names are organized by the agency providing data.

\subsection{Commuting Behavior and Demographics}

We collected commuting and demographic data for all cities in the sample from the 20052009 American Community Survey (ACS) 5-year estimates. The US Census Bureau administers the ACS on a rolling basis and provides aggregated estimates over varying timeframes. 5 -year estimates are more reliable than the other alternatives because they have a larger sample and longer timeframe. The commuting data was converted into a rate of bike commuters per 10,000 commuters. Demographic control variables included percentage of households with children under 18 , share of residents who are enrolled in college, auto ownership rates, median household income, total population, and number of workers. Auto ownership rates were constructed from an aggregate number of vehicles owned in the city and the number of households. College enrollment was included to control for possible outlier cases such as Davis, California.

Table 1 summarizes the commuting, demographic, and spatial variables in this study and their expected relationship with bicycle commuting. The very low rates of bicycle commuting are apparent here: the highest commute share in the study is $15.5 \%$ (Davis), but all other cities have commute shares below 7\% (not shown). The sample included a diverse range of incomes, household structures, and vehicle ownership rates.

The ACS data has several notable caveats. The survey asks respondents by which mode they traveled to work the most in the past week, so the dependent variable only measures bicycle commuting. Bike commuting may not be representative of bicycling for other trip purposes. Bike commuters are more likely to be frequent, confident cyclists than someone 
Table 1: Descriptive Statistics for Demographic/City Variables

\begin{tabular}{lrrrr}
\hline Variable & Average & Std. Deviation & Min & Max \\
\hline Bicyclists per 10,000 Workers & 116.0 & 210.6 & 5.1 & $1,547.5$ \\
Population & 488,185 & $1,089,012$ & 61,866 & $8,302,659$ \\
Land Area $\left(\mathrm{km}^{2}\right)$ & 218 & 243 & 17 & 1,214 \\
Median Income (\$USD) & $\$ 57,645$ & $\$ 13,937$ & $\$ 34,113$ & $\$ 97,160$ \\
Pct. Households with Kids & $35.9 \%$ & $9.4 \%$ & $15.9 \%$ & $56.3 \%$ \\
Pct. College Students & $9.1 \%$ & $5 . \%$ & $5 . \%$ & $35.9 \%$ \\
Vehicles per Household & 1.7 & 0.3 & 0.6 & 2.2 \\
\hline
\end{tabular}

Data from ACS 2005-2009

who bikes to meet a friend for coffee once a week, so an observed relationship between infrastructure and bike commuting may not be useful for identifying what other types of cyclists need from infrastructure.

Bicyclists tend to be multimodal; they may bike some days, but drive or use transit on other days when the weather is bad or when they have to travel for meetings or appointments during the workday (Heinen et al, 2010). Part-time bike commuters may be underrepresented because the ACS only allows for one single mode. The ACS year-round rolling sampling strategy introduces an incredible range of weather variability within and between cities. Finally, due to the sample size of the ACS and the relatively low numbers of bike commuters in each city, the standard error on these measures are very high; nonetheless, the ACS remains the only nationwide survey of travel behavior that can be used at this geographic resolution.

\subsection{Network Measures}

Graph edges represent segments of bicycle infrastructure (bike lanes, trails, sidepaths). Vertices represent intersections and endpoints within the bicycle infrastructure network (e.g., where two trails cross). The dataset does not contain any connections between the bicycle network and the remaining road network. For each city, we measured the number of edges $(e)$, number of vertices $(v)$, and the total length of all the edges, or graph length $(L)$.

We also measured an airline distance between the endpoints of each edge to calculate how direct each segment is. An overall directness measure was estimated using the cumulative difference between each edge's travel length and airline distance between its endpoints. The purpose of this measure is to gauge how much of a city's bike network is comprised of recreationally oriented paths that meander or circle back on themselves (e.g., paths winding through parks or circling around a lake), versus paths that provide an efficient utilitarian connection for commuting. Figure 2 shows four segments of infrastructure in Minneapolis's bicycle network to demonstrate direct versus indirect/recreational paths. The Hiawatha Trail and Minnehaha Avenue Bike Lanes are perfectly straight. Their lengths are equal to the airline distance between their endpoints. The East and West River Parkway Trails have a lot of curves to take advantage of the natural scenery along the river.

Many cities' bicycle networks are fragmented into sub-networks or subgraphs. Each distinct "island" of links within a city should be counted as a subgraph. However, some cities leave small gaps in the data where a bike lane crosses an intersection, even though the lanes on either side function as a single facility. These gaps were too large to resolve using the model routine described in Section 3.1. We generated a 10-meter buffer around all links and 


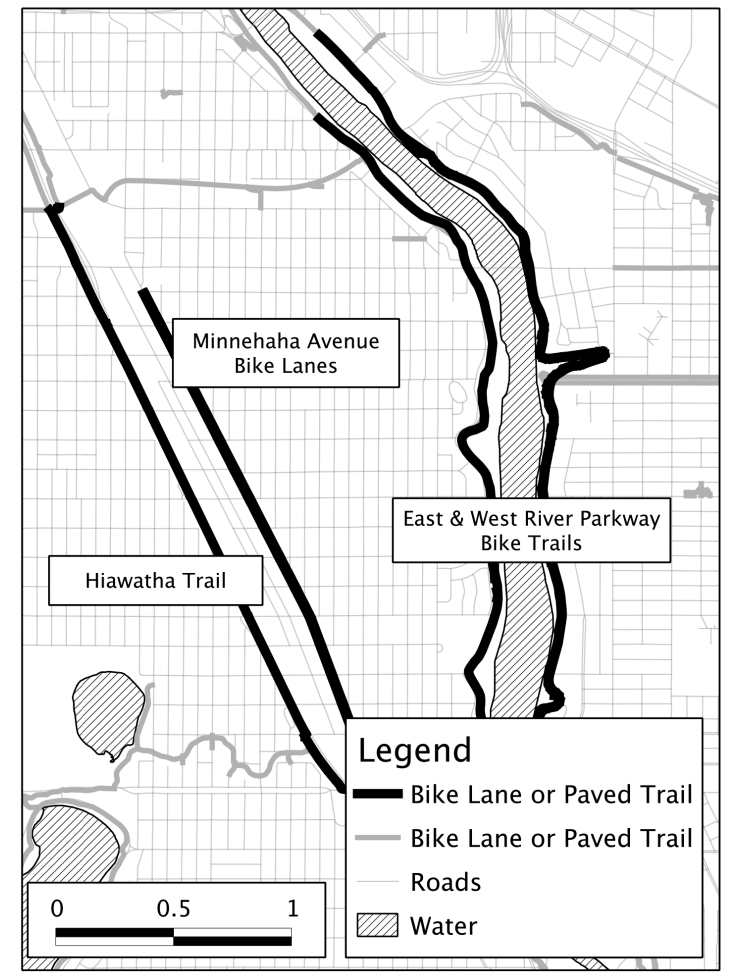

Fig. 2: Visual Comparison of Directness On Minneapolis Infrastructure

treated any link that intersected another link's buffer as part of the same subgraph. We then measured the number of subgraphs $(p)$, length of the largest subgraph, and average subgraph length. The relative size of the largest and average subgraphs were calculated by dividing by $L$. If the largest subgraph contains a high percentage of the bike network, this suggests one main network with smaller fragments. If the percent of the bike network contained by the average subgraph is relatively high, this suggests a more even distribution between two or more smaller but substantial subgraphs. Whether these scenarios are useful for bicyclists or a deterrent will depend on what types of road facilities connect the bike network fragments.

The $\alpha, \gamma$, and $\beta$ indices were calculated for each city based on Rodrigue et al (2009)'s description of the formulas. The beta index $(\beta)$ is a ratio of number of edges $(e)$ to number of vertices $(v)$, shown in Equation 1.

$$
\beta=\frac{e}{v}
$$

A collection of disconnected, non-intersecting edges has $\beta=0.5$ (see Equation 2.

$$
\begin{aligned}
v=2 e & \Rightarrow \\
& \frac{e}{v}=\frac{e}{2 e}=\frac{1}{2}
\end{aligned}
$$




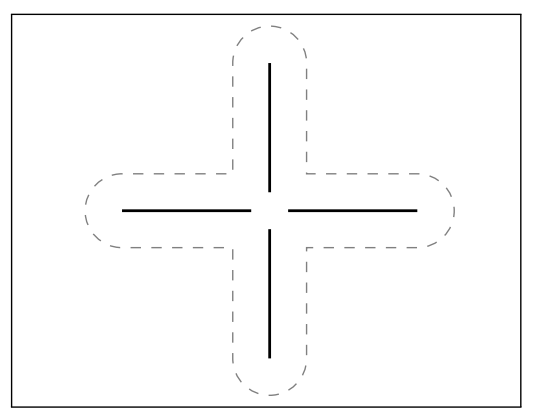

Fig. 3: Buffering process to identify subgraphs with small gaps

A bicycle network with a low $\beta$ suggests an increased chance that any given route requires leaving dedicated infrastructure to ride with mixed traffic. Adding links to a network, and thereby increasing the value of $\beta$, increases the complexity and the probability that any two given vertices have links between them. The gamma index $(\gamma)$ is closely related: it represents the number of observed edges $(e)$ to the theoretical maximum number of edges, estimated using Equation 3(Rodrigue et al, 2009).

$$
\gamma=\frac{e}{3(v-2)}
$$

$\gamma$ values range from 0 to 1 , with 0 indicating a cluster of vertices with no edges, and 1 indicating a fully connected graph. Higher values indicate greater internal connectivity and increased redundancy, though the excess redundancy associated with $\gamma \rightarrow 1$ makes these types of networks impractical (Rodrigue et al, 2009). In general, a more highly connected bicycle network should provide more direct paths than a less connected network.

Cycles are connected chains of edges with the same starting and ending point, and the number of cycles $(u)$ is estimated using Equation 4, where $p$ is the number of subgraphs.

$$
u=e-v+p
$$

The alpha index $(\alpha)$ is the ratio of $u$ to the theoretical maximum number of cycles, shown in Equation 5.

$$
\alpha=\frac{u}{2 v-5}
$$

Higher values of $u$ correspond to a higher level of complexity and development within the network. Simple networks or tree-like networks have no cycles. Like $\gamma, \alpha$ values range from 0 to 1 and values approaching 1 are highly unlikely due to excessive redundancies. Unlike $\gamma$, this measure is independent from the number of nodes and therefore should be less size-dependent (Rodrigue et al, 2009).

Table 2 provides descriptive statistics for all the network measures included in this study. It should be noted that the 50-meter buffer used to define subgraphs affected the estimates for number of cycles $(u)$ and $\alpha$ index calculations because the number of subgraphs measured this way is artificially low relative to the number of vertices. The minimum values of the $\alpha$ index and number of cycles $(u)$ are both negative, which is theoretically impossible according to the formulas, but feasible given how subgraphs were estimated in this study. 
Table 2: Descriptive Statistics for Bicycle Facility Network Variables

\begin{tabular}{|c|c|c|c|c|}
\hline Variable & Average & SD & Min & $\operatorname{Max}$ \\
\hline Length $(\mathrm{km})$ & 311.16 & 450.24 & 1.54 & 2204.22 \\
\hline Number of Edges & 190.58 & 246.98 & 1.00 & 1034.00 \\
\hline Number of Vertices & 202.34 & 239.18 & 2.00 & 1028.00 \\
\hline Number of Subgraphs & 31.54 & 34.75 & 1.00 & 168.00 \\
\hline Network Density $\left(\mathrm{km} / \mathrm{km}^{2}\right)^{*}$ & 1.74 & 2.67 & 0.03 & 18.67 \\
\hline Edge Density $\left(\# / \mathrm{km}^{2}\right)^{*}$ & 1.49 & 3.19 & 0.00 & 24.50 \\
\hline Subgraph Density $\left(\# / \mathrm{km}^{2}\right)^{*}$ & 0.22 & 0.26 & 0.00 & 1.45 \\
\hline Vertex Density $\left(\# / \mathrm{km}^{2}\right)^{*}$ & 1.55 & 2.80 & 0.01 & 20.24 \\
\hline Proportion Intersections & 0.26 & 0.17 & 0.00 & 0.64 \\
\hline Direct Length (km) & 275.70 & 408.57 & 1.38 & 1987.12 \\
\hline Avg. Length Ratio & 0.91 & 0.09 & 0.42 & 1.00 \\
\hline Minimum Length Ratio & 0.28 & 0.35 & 0.00 & 1.00 \\
\hline Overall Length Ratio & 0.86 & 0.11 & 0.42 & 1.00 \\
\hline Avg. Subgraph Length (km) & 11.84 & 21.29 & 0.77 & 155.12 \\
\hline Avg. Subgraph Percent & 0.15 & 0.24 & 0.01 & 1.00 \\
\hline Max Subgraph Length $(\mathrm{km})$ & 144.60 & 249.30 & 0.99 & 1621.75 \\
\hline Max Subgraph Percent & 0.49 & 0.26 & 0.13 & 1.00 \\
\hline Number of Cycles & 19.78 & 46.78 & -63.00 & 188.00 \\
\hline$\alpha$ Index & 0.03 & 0.05 & -0.07 & 0.17 \\
\hline$\gamma$ Index & 0.28 & 0.06 & 0.17 & 0.43 \\
\hline$\beta$ Index & 0.81 & 0.20 & 0.50 & 1.28 \\
\hline
\end{tabular}

The numbers of edges and vertices show the wide range of cities included in this study. Four cities in this sample have only a single link in their bicycle network $(e=1, v=2)$, while the largest city (New York) has over 1,000 edges. The bicycle networks represented in this sample are fragmented into an average of 32 subgraphs per network, and $26 \%$ of vertices are intersections (versus end points).

The average density of bike lanes and trails among these 74 cities is 1.74 kilometers per square kilometer of land in the city, with a range from $0.03 \# / \mathrm{km}^{2}$ to $18.67^{\#} / \mathrm{km}^{2}$. This sample has considerably denser networks than Dill and Carr (2003)'s cross-regional study of bicycle commuting $\left(0.38^{\#} / \mathrm{km}^{2}\right)$. Among the 21 cities included in both cities, these data suggest that bicycle facility density has increased by as much as $210 \%$ (from $0.51 \# / \mathrm{km}^{2}$ to 1.09 ) in the decade between data collection periods, depending on variation in data sources, accuracy, and measurement technique.

\subsection{Factor Analysis}

Many of the network variables were derived from the same set of spatial measurements, so they have a high degree of correlation with each other. To avoid multicollinearity issues in the regression model, principal component analysis with varimax rotation was used to identify underlying qualities from the list of 21 measures. The resulting five factors with eigenvalues greater than 1 characterize each network by its (1) size, (2) connectivity, (3) density, (4) fragmentation, and (5) directness.

Table 3 shows how variables load onto these factors. The size factor is mostly composed of variables measuring the number of network components (number of edges, vertices, sub- 
Table 3: Factor Loadings

\begin{tabular}{|c|c|c|c|c|c|}
\hline Variable & $\begin{array}{l}\text { Factor } 1 \\
\text { Size }\end{array}$ & $\begin{array}{c}\text { Factor } 2 \\
\text { Connectivity }\end{array}$ & $\begin{array}{l}\text { Factor } 3 \\
\text { Density }\end{array}$ & $\begin{array}{c}\text { Factor } 4 \\
\text { Fragmentation }\end{array}$ & $\begin{array}{c}\text { Factor } 5 \\
\text { Directness }\end{array}$ \\
\hline Length (km) & 0.965 & & & & \\
\hline Direct Length $(\mathrm{km})$ & 0.961 & & & & \\
\hline Number of Vertices & 0.851 & & & & \\
\hline Edges & 0.814 & & & & \\
\hline Number of Subgraphs & 0.790 & & & & \\
\hline Max Subgraph Length (km) & 0.793 & & & & \\
\hline$\alpha$ Index & & 0.895 & & & \\
\hline$\gamma$ Index & & 0.915 & & & \\
\hline Percent Intersections & & 0.908 & & & \\
\hline$\beta$ Index & & 0.910 & & & \\
\hline Number of Cycles & 0.536 & 0.627 & & & \\
\hline Avg. Length Ratio & & & & & 0.928 \\
\hline Overall Length Ratio & & & & & 0.937 \\
\hline Avg. Subgraph Pct. & & & & 0.720 & \\
\hline Max Subgraph Pct. & & & & 0.881 & \\
\hline Minimum Length Ratio & & & & & 0.511 \\
\hline Avg. Subgraph Length (km) & & & & 0.608 & \\
\hline Network Density $\left(\mathrm{km}^{-} \mathrm{km}^{2}\right.$ ) & & & 0.808 & & \\
\hline Vertices per $\mathrm{km}^{2}$ & & & 0.959 & & \\
\hline Edges per $\mathrm{km}^{2}$ & & & 0.921 & & \\
\hline Subgraphs per $\mathrm{km}^{2}$ & & & 0.734 & & \\
\hline
\end{tabular}

graphs), as well as measures of their overall length. Connectivity contains the $\alpha, \gamma$, and $\beta$ indices and percent of vertices that are intersections. The density factor characterizes both length of facility per unit area as well as number of components (edge, vertex, and subgraph density). Fragmentation represents the percent of the network contained in the largest and average subgraphs and the length of the average subgraph. Finally, the directness factor captures all ratio measures between the length of the path and the length of a straight line connecting the path's endpoints.

Factors are normalized to have a mean of 0 and standard deviation of 1 . Each city's factor scores are also relative to the sample used to construct the factors. For example, if a city has a connectivity factor value of 0 , that city can be considered average within the sample. A city with a connectivity factor of -1 would be one standard deviation lower than average, relative to all the cities included. Figure 4 demonstrates these differences for the network size factor by mapping cities with factor scores closest to $-1,0$, and +1 on the same scale.

\section{Results}

Table 4 shows the results of two linear regressions. In Model 1, the five network factors are used to model bicycle commuters per 10,000 commuters. The adjusted $\mathrm{R}^{2}$ for this model is 0.509 , suggesting that network structure measures explain about $50 \%$ of the variation in rates of bicycle commuting between cities in the sample. The connectivity and density factors are positive and significant. A one unit increase in the density factor (or one standard deviation, given how factor scores are normalized) corresponds to about 150 additional bicycle commuters per 10,000 commuters in the city, all else equal. Connectivity has a weaker 


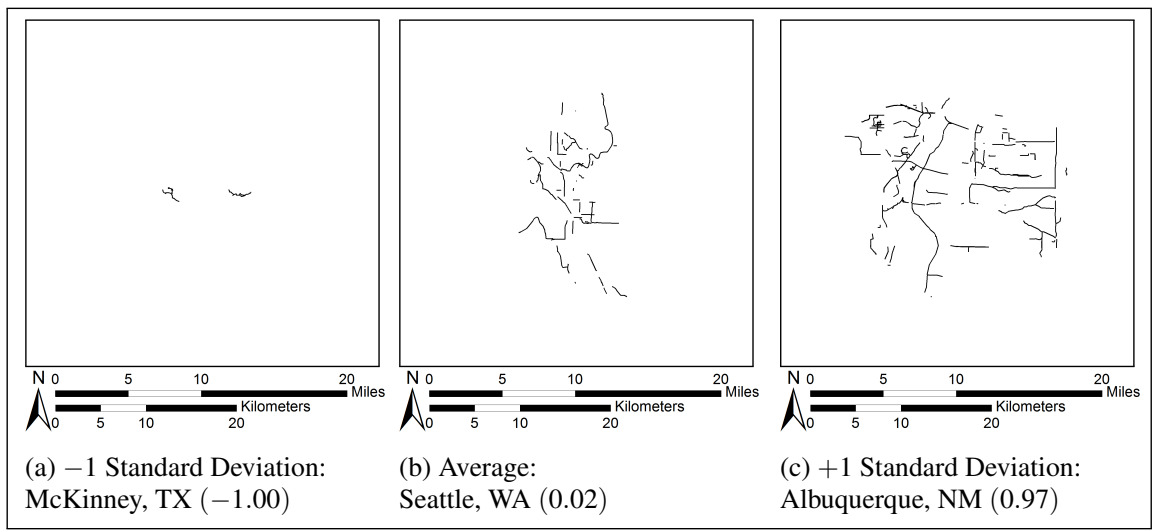

Fig. 4: Comparison of Network Size Factor Scores

Table 4: Regression Results

\begin{tabular}{|c|c|c|c|c|}
\hline \multirow[b]{2}{*}{ Variable } & \multicolumn{2}{|c|}{ Model 1} & \multicolumn{2}{|c|}{ Model 2} \\
\hline & Coefficient & SE & Coefficient & SE \\
\hline Factor 1: Size & -2.184 & 17.272 & -19.352 & 16.109 \\
\hline Factor 2: Connectivity & $37.351^{* *}$ & 17.272 & $22.426^{*}$ & 12.054 \\
\hline Factor 3: Density & $149.956^{* * *}$ & 17.272 & $89.846^{* * *}$ & 15.245 \\
\hline Factor 4: Fragmentation & 6.715 & 17.272 & $23.881^{*}$ & 12.720 \\
\hline Factor 5: Directness & 10.955 & 17.272 & $31.701^{* *}$ & 11.990 \\
\hline Area $\left(\mathrm{km}^{2}\right)$ & & & 0.113 & 0.073 \\
\hline Population $(1,000)$ & & & 0.006 & 0.018 \\
\hline Median Income $(\$ 1,000)$ & & & -1.407 & 1.072 \\
\hline Pct. HH with Kids & & & -2.975 & 2.111 \\
\hline Pct. College Students & & & $22.398^{* * *}$ & 3.232 \\
\hline Vehicles per $\mathrm{HH}$ & & & 1.920 & 69.564 \\
\hline Constant & $116.045^{* * *}$ & 17.155 & 68.507 & 98.296 \\
\hline $\mathrm{R} 2$ & 0.543 & & 0.833 & \\
\hline Adj R2 & 0.509 & & 0.804 & \\
\hline Avg VIF & 1.000 & & 2.300 & \\
\hline
\end{tabular}

relationship, with a one unit change associated with an increase of 37 bicyclists. The standard errors for all coefficients in Model 1 are equal because all explanatory variables in this model are normalized to have a mean of 0 and standard deviation of 1 .

Model 2 controls for city size and demographic and economic characteristics. The adjusted $\mathrm{R}^{2}$ for this model is 0.804 , which represents a considerable improvement over the network only model. In this model, density and connectivity are still positive and significant, along with fragmentation and directness. Among the control variables, percent college students is the only significant one, with each additional percentage point increase in population enrolled in college corresponding to about 22 additional bicyclists per 10,000. The Average VIF scores for both models are quite low, suggesting that factor analysis addresses any possible multicollinearity issues between similarly constructed network measures. We repeated the analysis using robust standard errors to account for heteroscedasticity arising 
Table 5: Elasticity of Bicycle Commuting to Network Factors

\begin{tabular}{lrrrrr}
\hline \multicolumn{1}{c}{ Change Variable: } & $+1 \%$ & +0.01 & +0.25 & +0.5 & +1 Std. Dev. \\
\hline Factor 1: Size & $0.00 \%$ & $-0.17 \%$ & $-4.17 \%$ & $-8.34 \%$ & $-16.68 \%$ \\
Factor 2: Connectivity* & $0.00 \%$ & $0.19 \%$ & $4.83 \%$ & $9.66 \%$ & $19.33 \%$ \\
Factor 3: Density*** & $0.00 \%$ & $0.77 \%$ & $19.36 \%$ & $38.71 \%$ & $77.42 \%$ \\
Factor 4: Fragmentation* & $0.00 \%$ & $0.21 \%$ & $5.14 \%$ & $10.29 \%$ & $20.58 \%$ \\
Factor 5: Directness** & $0.00 \%$ & $0.21 \%$ & $5.14 \%$ & $10.29 \%$ & $27.32 \%$ \\
\hline
\end{tabular}

Elasticities computed with all other variables evaluated at means.

Factors are normalized to $\mu=0$ and $\sigma=1$.

${ }^{*},{ }^{* *},{ }^{* * *}$ Variable was significant in Model 2 at $p<.1, p<.05$, or $p<.01$

Table 6: Elasticity of Bicycle Commuting to City Size and Demographics

\begin{tabular}{lrrrrr}
\hline \multicolumn{1}{c}{ Change in Variable: } & $+1 \%$ & $+25 \%$ & $+50 \%$ & $+100 \%$ & +1 Std. Dev. \\
\hline Population $(1,000)$ & $0.03 \%$ & $0.66 \%$ & $1.32 \%$ & $2.63 \%$ & $5.87 \%$ \\
Area $\left(\mathrm{km}^{2}\right)$ & $0.21 \%$ & $5.29 \%$ & $10.58 \%$ & $21.17 \%$ & $23.67 \%$ \\
Median Income $(\$ 1,000)$ & $-0.70 \%$ & $-17.48 \%$ & $-34.96 \%$ & $-69.92 \%$ & $-16.90 \%$ \\
Pct. HH with Kids & $-0.92 \%$ & $-23.00 \%$ & $-46.01 \%$ & $-92.02 \%$ & $-24.11 \%$ \\
Pct. College Students*** & $1.76 \%$ & $44.09 \%$ & $88.17 \%$ & $176.34 \%$ & $96.73 \%$ \\
Vehicles per HH & $0.03 \%$ & $0.69 \%$ & $1.38 \%$ & $2.76 \%$ & $0.53 \%$ \\
\hline Elasticities computed with all other variables evaluated at means. \\
$*, * *, * * *$ Variable was significant in the regression model at the $p<.1, p<.05$, or $p<.01$ level.
\end{tabular}

from the diverse sample of city sizes and populations, but this did not change the significance of any variables at the thresholds indicated.

\subsection{Elasticity}

Table 5 shows sensitivity of bicycle commuting to changes in network factor scores using the regression results in Model 2. Since factor scores are relative to the cities within the sample and normalized to have a mean of 0 and a standard deviation of 1 , representing a $1 \%$ increase from $\mu=0$ is meaningless. Elasticities are calculated based on adding 0.01, 0.25, 0.5 , and 1.0 to the mean factor score. Bicycle commuting is most sensitive to changes in network density. A change in the density factor score from 0 to 1 (or one standard deviation) corresponds to a $77 \%$ increase in rates of bicycle commuting. Increasing a city's connectivity score or fragmentation score from 0 to 1 is associated with about a $20 \%$ increase in biking, and the same change in directness corresponds to a $27 \%$ change in the dependent variable.

Table 6 shows the same sensitivity calculations for city size and demographic variables. College enrollment is the only significant size or demographic variable in the model, and bicycle commuting is more sensitive to changes in college enrollment than all other network, size, and demographic variables alike. A one percent increase in college enrollment corresponds to a $1.76 \%$ increase in bike commuting. Increasing college enrollment by one standard deviation (5 percentage points) is associated with a $97 \%$ increase.

\section{Discussion}

The regression model results show that a city's bicycle commuting rate is associated with several network structure measures, even after controlling for the city's size, population, 
median income, household structure, college enrollment, and vehicle ownership. The density factor had the strongest coefficient and elasticity: a one standard deviation increase in network density corresponded to a larger increase in bicycle commuting than one standard deviation increases in connectivity, fragmentation, and directness combined. Although the network factor scores are relative to this particular sample, the results from this study still demonstrate the relative importance of network characteristics for biking.

The measures that loaded onto the density factor are density of facilities (kilometers per square kilometer), density of edges and vertices, and density of subgraphs. These findings suggest that cities hoping to maximize the impacts of their bicycle infrastructure investments should first consider densifying their bicycle network before expanding its breadth.

Fragmentation has the potential to affect bicyclists in a number of ways. A series of careless, one-off projects could leave bicyclists without adequate routes across the city, but strategically installing bike lanes or trails to augment a comfortable residential street network could expand cyclists' mobility opportunities. The fragmentation factor is composed of the share of bike network contained in the largest subgraph and average subgraph, and the length of the average subgraph (Table 3 ). The coefficient on the fragmentation factor is positive and significant in Model 2 (Table 4). This suggests that having either an even distribution of reasonably sized fragments (large share of bike network in average subgraph) or one dominant section (large share of bike network in largest subgraph) facilitates bicycling, but excessive fragmentation with small fragments should be avoided.

The $\gamma$ and $\beta$ indices were the strongest loadings on the connectivity factor. Additionally, the strongest loading in the fragmentation factor was the percent of the network contained in the largest subgraph. If an agency has the funds to build one new bike lane, they could capitalize on the significance of the connectivity, fragmentation, and density factors simultaneously by making the new link intersect with parts of the existing network within the largest subgraph or linking the largest subgraph to adjacent ones. The mere fact of adding facility densifies the network, while targeting its placement to connect to existing links and expand the largest subgraph improves the connectivity and fragmentation scores respectively.

The results also showed that college enrollment was a strong predictor for bicycle commuting, with an even stronger elasticity than the network measures. While this is not surprising, it does highlight how bicycle commuting may be more useful or practical for certain segments of the population than others. This has several possible policy implications. First, it is clear that college towns will always have an edge for rates of bicycle commuting. Building a new college or university may attract a new population of bicycling residents. More practically, agencies could consider whether infrastructure investments around a college would have a smaller or larger marginal effect than investments in other parts of the city. If a college has weak rates of bicycle commuting, targeting network development between campus and neighborhoods where students tend to live may have a bigger impact than an equivalent investment in another part of the network.

\subsection{Limitations and Areas for Future Study}

As discussed throughout this study, data issues are always a concern when studying bicycling. Bicycling has a small commute mode share and the characteristics of the mode make its users more vulnerable to distance, climate, and weather. Typical sampling strategies for the ACS do not capture the full range of bicycling that occurs in any given city. Additionally, bicycle infrastructure data is sparse and lacks the industry-wide standard for creation, maintenance, storage, and distribution that we have for most road networks. Building a sample 
from cities that publish their bicycle network data biases the sample toward cities that value bicycling.

Studying aggregate travel behavior does not necessarily imply individual effects or outcomes. The graph theory measures employed here characterize the bicycle network's structure, but they do not account for the built environment context surrounding the bicycle network. At the individual level, the overall bike network structure might not matter much, as long as the commute trip distance is appropriate for bicycling and the individual has a route they feel comfortable with connecting their home and work. One way to address this in future research is through measuring accessibility to jobs or other destinations that the network provides. Between-city variation in policy, weather, topography, and other contexts also may influence results. Additionally, aggregate studies are vulnerable to deceptively high adjusted $\mathrm{R}^{2}$ values because aggregation smooths out individual variability. Therefore the strength of our model may be overstated.

While insignificant in this model, some demographic factors such as gender and households with children are negatively associated with bicycling. Weak or negative relationships between demographic groups and bicycling should not be used as an excuse to completely divest from certain neighborhoods. Further study is needed to fully explain infrastructure and other barriers to cycling, and to identify what other kinds of bicycle trips beyond commuting could be made accessible through strategically building out the bicycle network.

This study treated on-street and off-street dedicated infrastructure (bike lanes and paved trails) interchangeably for purposes of measuring network structure because they both provide a designated space for bikes, versus newer or experimental treatments like shared lane markings or bike boulevards. However, existing research shows that bicyclists value these facility types differently. Tilahun et al (2007)'s stated preference survey findings suggest that cyclists value the presence of a bike as equivalent to saving about 16 minutes of travel time, while off-road improvements add less value than a quiet street without on-street parking (5 and 9 minutes respectively). Sanders (2014)'s results suggest that bicyclist comfort level in a bike lane varies based buffers, barriers, and on-street parking. Klobucar and Fricker (2007) demonstrated the use of Bicycle Compatibility Index (BCI) to model the effects of building new dedicated bike infrastructure on compatible and incompatible streets, which points to the information we miss by not evaluating the streets on which the bike lanes are built. Mixed traffic facilities such as shared lane markings, signed bike routes, and bike boulevards were completely excluded because they vary so widely in quality and definition. This study sheds light on the desperate need for standardized data collection and management practices for bicycle infrastructure networks and nonmotorized travel behavior. Given more standardized data, future study should consider hierarchies of infrastructure types within bicycle networks and complementary street networks and what effects these have on bicycling.

Acknowledgements The authors are grateful for the feedback from three anonymous reviewers whose feedback greatly improved the quality of the paper.

\section{References}

American Association of State Highway and Transportation Officials (2012) Guide for the Development of Bicycle Facilities, 4th edn. American Association of State Highway and Transportation Officials, Washington, D.C., URL http://books.google.com/books?hl=en\&lr=\&id=XAI3Z1xp828C\&oi= 
fnd\&pg=PP4\&dq=Guide+for+the+Development+of+Bicycle+Facilities\&ots $=$ OLtBrL21dy\&sig=pTxWvDpkZcCQmypbU78JuAR2gb0

Barnes G, Krizek K (2005) Estimating Bicycling Demand. Transportation Research Record 1939:45-51, DOI 10.3141/1939-06, URL http://trb.metapress.com/openurl. asp?genre=article\&id=doi : 10 .3141/1939-06

Berrigan D, Pickle LW, Dill J (2010) Associations between street connectivity and active transportation. International Journal of Health Geographics 9(20), DOI 10.1186/ 1476-072X-9-20, URL http://www.pubmedcentral.nih.gov/articlerender. fcgi? artid=2876088\&tool=pmcentrez\&rendertype=abstract

Birk M, Geller R (2006) Bridging the Gaps: How Quality and Quantity of a Connected Bikeway Network Correlates with Increasing Bicycle Use. TRB 85th Annual Meeting Compendium of Papers \#06-0667, URL http://trid.trb.org/view . aspx?id=776458

Buehler R, Pucher J (2011) Cycling to work in 90 large American cities: new evidence on the role of bike paths and lanes. Transportation 39(2):409-432, DOI 10. 1007/s11116-011-9355-8, URL http://www.springerlink.com/index/10.1007/ s11116-011-9355-8

Buehler R, Pucher J (2012) Walking and Cycling in Western Europe and the United States: Trends, Policies, and Lessons. TR News 280:34-42, URL http: //onlinepubs.trb.org/onlinepubs/trnews/trnews280.pdf\#page=36http: //trid.trb.org/view. aspx?id=1143635

Byers RH (2002) Hennepin County Bicycle System Gap Study. Tech. Rep. March, Hennepin County, URL http://www.hennepin.us/files/HennepinUS/Transportation/ BikewaysandTrails/BicyclePlanning/BikeGapStudyFull.pdf

Caulfield B, Brick E, McCarthy OT (2012) Determining bicycle infrastructure preferences A case study of Dublin. Transportation Research Part D: Transport and the Environment 17(5):413-417, DOI 10.1016/j.trd.2012.04.001, URL http://linkinghub. elsevier.com/retrieve/pii/S1361920912000363

Derrible S, Kennedy C (2009) Network Analysis of World Subway Systems Using Updated Graph Theory. Transportation Research Record: Journal of the Transportation Research Board 2112(-1):17-25, DOI 10.3141/2112-03, URL http://trb.metapress . com/openurl . asp?genre=article\&id=doi : 10 .3141/2112-03

Dill J (2009) Bicycling for transportation and health: the role of infrastructure. Journal of public health policy 30 Suppl 1(1):S95-110, DOI 10.1057/jphp.2008.56, URL http: //www.ncbi.nlm.nih.gov/pubmed/19190585

Dill J, Carr T (2003) Bicycle commuting and facilities in major US cities: if you build them, commuters will use them. Transportation Research Record pp 116-123, URL http:// trb.metapress.com/index/A2485322G1249615.pdf

Dill J, Voros K (2007) Factors Affecting Bicycling Demand: Initial Survey Findings from the Portland, Oregon, Region. Transportation Research Record 2031:9-17, DOI 10.3141/2031-02, URL http://trb.metapress.com/openurl.asp?genre= article\&id=doi: $10.3141 / 2031-02$

Federal Highway Administration (2012) Report to the U. S. Congress on the Outcomes of the Nonmotorized Transportation Pilot Program SAFETEA-LU Section 1807. Tech. Rep. April, Submitted by the Federal Highway Administration With the Assistance of the U.S. Department of Transportation's Volpe National Transportation Systems Center, Washington, D.C.

Garrison WL, Marble DF (1962) The structure of transportation networks. Tech. rep., Northwestern University, Evanston 
Handy SL, Xing Y (2011) Factors Correlated with Bicycle Commuting: A Study in Six Small US Cities. International Journal of Sustainable Transportation 5(2):91-110, DOI 10.1080/15568310903514789, URL http://www.tandfonline.com/doi/abs/ 10.1080/15568310903514789

Heinen E, van Wee B, Maat K (2010) Commuting by Bicycle: An Overview of the Literature. Transport Reviews 30(1):59-96, DOI 10.1080/01441640903187001, URL http: //www.tandfonline.com/doi/abs/10.1080/01441640903187001

Kansky KJ (1963) Structure of Transportation Networks. Doctoral dissertation, University of Chicago

Klobucar MS, Fricker JD (2007) Network Evaluation Tool to Improve Real and Perceived Bicycle Safety. Transportation Research Record 2031:25-33, DOI 10.3141/ 2031-04, URL http://trb.metapress.com/openurl.asp?genre=article\&id= doi:10.3141/2031-04

Krizek K, Barnes G, Thompson K (2009) Analyzing the effect of bicycle facilities on commute mode share over time. Journal of Urban Planning and Development (June):66-73, DOI 10.1061/?ASCE?0733-9488?2009?135:2?66?CE, URL http://ascelibrary . org/doi/abs/10.1061/(ASCE) 0733-9488 (2009) 135\%3A2 (66)

Krizek KJ, Roland RW (2005) What is at the end of the road? Understanding discontinuities of on-street bicycle lanes in urban settings. Transportation Research Part D: Transport and the Environment 10(1):55-68, DOI 10.1016/j.trd.2004.09.005, URL http: //linkinghub.elsevier.com/retrieve/pii/S1361920904000628

Mekuria MC, Furth PG, Nixon H (2012) Low-Stress Bicycling and Network Connectivity. Tech. rep., Mineta Transportation Institute, San Jose

Nelson A, Allen D (1997) If you build them, commuters will use them: associaiton between bicycle facilities and bicycle commuting. Transportation Research Record URL http: //trb.metapress.com/index/5573wq3237qh4g01.pdf

Parkin J, Wardman M, Page M (2007) Estimation of the Determinants of Bicycle Mode Share for the Journey to Work Using Census Data. Transportation 35(1):93-109, DOI 10. 1007/s11116-007-9137-5, URL http://www.springerlink.com/index/10.1007/ s11116-007-9137-5

Parthasarathi P, Levinson D, Hochmair H (2013) Network structure and travel time perception. PloS one 8(10):e77,718, DOI 10.1371/journal.pone.0077718, URL http://www.pubmedcentral.nih.gov/articlerender.fcgi?artid= 3812229\&tool=pmcentrez\&rendertype=abstract

Pratt RH, Levinson HS, Turner SM, Jeng CY, Nabors D (2012) Pedestrian and Bicycle Facilities. In: TCRP Report 95: Traveler Response to Transportation System Changes, Transportation Research Board, Washington, D.C., chap 16, URL http://trid.trb. org/view . aspx?id=171542

Pucher J, Komanoff C, Schimek P (1999) Bicycling renaissance in North America?: Recent trends and alternative policies to promote bicycling. Transportation Research Part A 33(212), URL http://www.sciencedirect.com/science/article/pii/ S0965856499000105

Rietveld P, Daniel V (2004) Determinants of bicycle use: do municipal policies matter? Transportation Research Part A: Policy and Practice 38(7):531-550, DOI 10. 1016/j.tra.2004.05.003, URL http://linkinghub.elsevier.com/retrieve/pii/ S0965856404000382

Rodrigue JP, Comtois C, Slack B (2009) The Geography of Transport Systems, 2nd edn. Routledge, New York, NY, URL http://books.google.com/books/about/The_ Geography_of_Transport_Systems.html?id=afRodkxRoCsC\&pgis=1 
Sanders RL (2014) Roadway Design Preferences Among Drivers and Bicyclists in the Bay Area. TRB 93rd Annual Meeting Compendium of Papers \#14-5454

Stinson MA, Bhat CR (2005) A Comparison of the Route Preferences of Experienced and Inexperienced Bicycle Commuters. TRB 84th Annual Meeting Compendium of Papers \#05-1434

Tilahun NY, Levinson DM, Krizek KJ (2007) Trails, lanes, or traffic: Valuing bicycle facilities with an adaptive stated preference survey. Transportation Research Part A 41(4):287-301, DOI 10.1016/j.tra.2006.09.007, URL http://linkinghub. elsevier.com/retrieve/pii/S096585640600108X

Wilkinson W, Clarke A, Epperson B, Knoblauch R (1994) Selecting Roadway Design Treatments to Accommodate Bicycles. Tech. Rep. January, USDOT Federal Highway Administration, Great Falls, VA

Xie F, Levinson D (2007) Measuring the Structure of Road Networks. Geographical Analysis 39(3):336-356, DOI 10.1111/j.1538-4632.2007.00707.x, URL http://doi . wiley . $\mathrm{com} / 10.1111 / \mathrm{j} .1538-4632.2007 .00707 . \mathrm{x}$

Zhao P (2013) The Impact of the Built Environment on Bicycle Commuting: Evidence from Beijing. Urban Studies DOI 10.1177/0042098013494423, URL http://usj . sagepub. com/cgi/doi/10.1177/0042098013494423 